\title{
Keefektifan Metode Microskill Untuk Meningkatkan Kualitas Supervisi Klinik
}

\author{
Sunarko*, Ova Emilia**, Harsono Mardiwiyoto** \\ * Program Studi Keperawatan Magelang, Poltekes Kemenkes Semarang \\ ** Fakultas Kedokteran Universitas Gadjah Mada Yogyakarta
}

\begin{abstract}
Background: Clinical education requires competent supervisor to guide student. Supervisory competency should be trained and closely monitored to ensure quality learning process taking place.

Objective: The aim of this study is to evaluate the effect of microskill supervisory model to improve the supervision quality among nursing student.

Method: The research used quantitative approach with quasi experimental design. Subject consisted 91 students of the third year Nursing students at Magelang Health Polytechnic. Students were divided into two groups: intervention group (44 students) and control group (47 students) using purposive sampling. Research questionaire consisted of 21 items which were derived from 5 micro skill domains was used. Intervention was supervision using microskill model during 2 weeks in a rotation of clinical practice.

Result: There was no difference of quality clinical supervision was used in the control group while in experiment group the pre and post test score was significantly different. The experiment group had higher quality of supervision. The study showed that only 9 items showed significant improvement of supervision and 12 items did not show any improvement. Conclusion: Clinical teaching using micro skill model is more effective in improving the quality of nursing student clinical supervision compare to the conventional method.
\end{abstract}

Keywords: Nursing education, micro skill, one-minute preceptor, clinical supervision, supervisor, clinical teaching

\section{Abstrak}

Latar Belakang: Pendidikan klinik membutuhkan supervisor yang mempunyai kemampuan dalam membimbing praktik klinik mahasiswa. Untuk mencapai kemampuan itu, mereka harus disiapkan sesuai dengan kondisi yang dibutuhkan.

Tujuan: Penelitian ini bertujuan untuk menilai pengaruh pembelajaran klinik model microskill terhadap kualitas supervisi klinik pada mahasiswa keperawatan.

Metode: Pendekatan penelitian ini adalah kuantitatif dengan desain penelitian eksperimental semu. Subjek penelitian terdiri dari 91 mahasiswa tahun ketiga Program Studi Keperawatan Magelang Politeknik Kesehatan Departemen Kesehatan Semarang. Kelompok eksperimen terdiri dari 44 mahasiswa dan kelompok kontrol terdiri dari 47 mahasiswa dengan metode pengambilan sampel purposive sampling. Kuesioner penelitian terdiri dari 21 item yang dikembangkan dari 5 domain microskills. Intervensi yang diberikan adalah model pembelajaran klinik model microskill, yang dilakukan selama 2 minggu dalam 1 rotasi praktik klinik.

Hasil: Tidak ada perbedaan kualitas supervisi klinik antara pretest dan posttest pada kelompok kontrol, sedangkan pada kelompok eksperimen ada perbedaan signifikan. Kualitas supervisi juga berbeda signifikan antara kelompok kontrol dan kelompok eksperimen. Dari analisis perbedaan mean dari 21 item, 9 item mengalami peningkatan kualitas supervisi, sedangkan 12 item tidak mengalami peningkatan.

Kesimpulan: Pembelajaran klinik menggunakan model microskill lebih efektif jika dibandingkan dengan pembelajaran klinik yang konvensional, dalam meningkatkan kualitas supervisi klinik.

Kata Kunci: pendidikan keperawatan, microskills, one-minute preceptor, supervisi klinik, pembimbing klinik, pembelajaran klinik.

Korespondensi: sunarko181@gmail.com;0293-365185 


\section{PENDAHULUAN}

Pendidikan klinik memerlukan dukungan kemampuan supervisor klinik dalam membimbing agar peserta didik mampu mengembangkan kemampuan klinik, penalaran klinik dan profesionalismenya. ${ }^{1}$ Pembelajaran klinik menuntut mahasiswa untuk berpartisipasi aktif dalam berfikir dan berperilaku profesional. Untuk mencapai target kompetensi dan juga menghindari permasalahan yang kompleks dalam pendidikan klinik maka diperlukan proses bimbingan yang terus-menerus dan terencana. ${ }^{2}$

Salah satu faktor penentu keberhasilan pendidikan klinik adalah pembimbing harus mengetahui tujuan pendidikan klinik dan menjelaskannya kepada mahasiswa. Selain itu, di dalam pemberian feedback hendaknya pembimbing menggunakan teknik yang konstruktif. Pembimbing klinik harus mendapat pelatihan agar menjadi pembimbing yang efektif termasuk dalam hal tata cara evaluasi mahasiswa. ${ }^{3}$ Squires ${ }^{4}$ mengemukakan bahwa pendidikan klinik membutuhkan supervisor klinik yang mempunyai kemampuan membimbing mahasiswa. Untuk mencapai kemampuan itu, mereka harus dipersiapkan agar mencapai kondisi yang diinginkan.

Politeknik Kesehatan Kemenkes Semarang, merupakan institusi pendidikan yang menghasilkan tenaga kesehatan. Sesuai dengan visinya yaitu mandiri dan unggul dengan salah satu misi pentingnya yaitu melaksanakan kegiatan pendidikan dan pengajaran ilmu pengetahuan dan teknologi mutakhir bidang kesehatan kepada mahasiswa, sudah semestinya program pengajaran dan praktik klinik menerapkan hasil-hasil penelitian yang terkini di bidang kesehatan. Hal ini untuk menunjang mutu lulusan yang diharapkan dapat bersaing di tingkat regional maupun global.

Salah satu Program Studi yang ada adalah Program Studi Keperawatan Magelang yang menghasilkan perawat kesehatan. Untuk menghasilkan lulusan yang bermutu diperlukan proses pendidikan yang bermutu, baik proses belajar mengajar di kelas maupun proses bimbingan kliniknya. Dalam hal bimbingan klinik, metode bimbingan yang diterapkan oleh institusi yaitu bedside teaching, meskipun di lapangan sekitar $40 \%$ dosen pembimbing klinik belum memahami metode tersebut. Sehingga model bimbingan yang diterapkan di tempat praktik klinik cenderung sesuai dengan gaya bimbingan masing-masing dosen pembimbing klinik. Belum seragamnya model bimbingan yang baku mungkin merupakan salah satu faktor yang mempengaruhi kualitas bimbingan. Oleh karena itu diperlukan suatu model bimbingan yang lebih mudah dipahami sekaligus mudah dilakukan oleh seluruh dosen pembimbing klinik.

Menurut penilaian mahasiswa, sekitar 50\% mahasiswa menyatakan bahwa bimbingan praktik klinik yang diberikan kepada mahasiswa masih dalam bentuk seperti perkuliahan di kelas. Dalam hal ini dosen pembimbing klinik lebih menekankan pembuatan laporan praktik klinik daripada memberikan bimbingan klinik selama proses kegiatan klinik, selain itu target pembuatan laporan praktik klinik dirasakan sangat membebani mahasiswa. Mahasiswa disibukkan dalam menyusun laporan praktik klinik, sehingga pencapaian keterampilan klinik menjadi tidak maksimal.

Di samping itu, sekitar 30\% dosen pembimbing praktik klinik dalam memberikan bimbingan klinik belum mentaati jadwal yang ditetapkan oleh institusi. Sehingga mahasiswa terpaksa berkonsultasi dengan pembimbing di kampus pada saat mahasiswa praktik klinik. Hal ini membuat waktu praktik klinik akan tersita hanya untuk konsultasi pembuatan laporan praktik klinik di kampus.

Dari latar belakang tersebut diperlukan suatu pendekatan pembimbingan untuk meningkatkan kualitas pendidikan keperawatan. Penelitian ini bertujuan untuk mengetahui keefektifan pembelajaran klinik model micro skill untuk meningkatkan kualitas supervisi klinik mahasiswa keperawatan.

\section{METODE PENELITIAN}

Penelitian ini menggunakan pendekatan kuantitatif dengan rancangan penelitian eksperimen semu. Subjek penelitian terdiri dari 91 mahasiswa tahun ketiga Program Studi Keperawatan Magelang Politeknik Kesehatan Kementerian Kesehatan Semarang. Kelompok perlakuan dipilih pada dua RS terdiri dari 44 mahasiswa (11 orang laki-laki dan 33 orang perempuan) dan kelompok kontrol dipilih dari dua RS yang berbeda terdiri dari 47 mahasiswa (14 orang laki-laki dan 33 orang perempuan). Pemilihan RS dilakukan secara acak. RS terpilih yaitu di RSUD Tidar Magelang, RSUD Kabupaten Magelang, RSUD Djojonegoro Temanggung, dan RSJ Prof. dr. Soeroyo Magelang. Kuesioner penelitian terdiri dari 21 aitem yang dikembangkan dari 5 domain microskill. Intervensi yang diberikan adalah 
proses pembimbingan dengan menggunakan model microskill, yang dilakukan selama 2 minggu dalam 1 rotasi praktik klinik. Analisis data yang dipakai menggunakan uji beda t-test.

\section{HASIL}

Pada penelitian ini seluruh kuesioner mahasiswa dikembalikan kepada peneliti (response rate 100\%). Usia rata-rata responden adalah $20_{2} .48$ tahun. Adapun dosen yang memberikan bimbingan klinik seluruhnya berjumlah 11 orang, terdiri dari 6 laki-laki dan 5 perempuan. Dosen di kelompok kontrol sejumlah 6 orang, terdiri dari 3 laki-laki dan 3 perempuan dengan pendidikan S2 sejumlah 2 orang dan S1 sejumlah 4 orang. Sedangkan pada kelompok perlakuan jumlah dosennya adalah 5 orang terdiri dari 3 laki-laki dan 2 perempuan, seluruhnya berpendidikan S2.

Kualitas supervisi klinik sebelum dan sesudah rotasi klinik pada kedua kelompok tampak pada Tabel 1.

Tabel 1. Kualitas supervisi klinik kelompok kontrol dan kelompok perlakuan

\begin{tabular}{c|ccccc}
\multirow{2}{*}{ Variabel } & Kelompok & Mean & SD & Mean & Serlakuan \\
\cline { 2 - 6 } & Pretest & 2,48 & 0,22 & 2,50 & 0,23 \\
\cline { 2 - 6 } $\begin{array}{c}\text { Kostest } \\
\text { Kualitas Supervisi } \\
\text { Klinik }\end{array}$ & Mean change & 0,54 & 0,29 & 2,76 & 0,26 \\
\cline { 2 - 6 } & T & & 0,14 & 0,24 & $-8,31$ \\
\cline { 2 - 6 } & p value & $-1,82$ & & 0,00 \\
\hline
\end{tabular}

Pada kelompok kontrol perubahan persepsi kualitas supervisi klinik tidak bermakna $(\mathrm{p}=0,08)$ sedangkan pada kelompok perlakuan perubahan tersebut bermakna. Bila dibandingkan perubahan mean kualitas supervisi klinik antara kelompok kontrol dengan kelompok perlakuan, terdapat perbedaan signifikan seperti ditunjukkan pada Tabel 2.

Tabel 2. Kualitas supervisi klinik antara mean kelompok kontrol dan mean kelompok perlakuan

\begin{tabular}{|c|c|c|c|c|c|}
\hline Variable & Mean & Std. Deviation & $\begin{array}{c}\text { Mean } \\
\text { difference }\end{array}$ & $\mathrm{T}$ & $P$ value \\
\hline $\begin{array}{c}\text { Kelompok } \\
\text { kontrol }\end{array}$ & 0,06 & 0,14 & \multirow{2}{*}{0,20} & \multirow{2}{*}{4,57} & \multirow{2}{*}{0,00} \\
\hline $\begin{array}{l}\text { Kelompok } \\
\text { perlakuan }\end{array}$ & 0,24 & 0,15 & & & \\
\hline
\end{tabular}

Untuk menganalisis aitem perubahan dalam kualitas supervisi dilakukan $t$ test (Tabel 3). Dari hasil analisis ini didapatkan 9 aitem yang signifikan berubah dari total 21 aitem. Aitem yang berubah signifikan menunjukkan aitem dalam supervisi yang mungkin lebih mudah untuk diubah, aitem berikut dinilai berbeda signifikan, "dosen pembimbing praktik klinik memberikan kesempatan untuk mempresentasikan kasus pasien", "menanyakan rencana keperawatan pasien", "menanya- kan rencana keperawatan yang telah dilakukan", "meminta untuk memberikan data yang mendukung diagnosis keperawatan yang disampaikan", "memberikan pujian apabila tindakan yang dilakukan benar", "memberikan cara bagaimana menghindari kesalahan", "mengajarkan konsep seputar kasus yang dipresentasikan", "mendorong mengaplikasikan konsep dalam melakukan praktik klinik", "membimbing dengan rasa percaya diri”. 
Tabel 3. Skor kualitas supervisi klinik antara kelompok kontrol dan kelompok perlakuan

\begin{tabular}{|c|c|c|c|c|c|c|c|c|}
\hline \multirow{3}{*}{$\begin{array}{c}\text { Per } \\
\text { sepsi } \\
\text { Aitem }\end{array}$} & \multicolumn{6}{|c|}{ Tabulasi Data Kualitas Supervisi Klinik } & \multirow{3}{*}{$\begin{array}{c}\text { Mean } \\
\text { difference in } \\
\text { change } \\
\text { between } \\
\text { group }\end{array}$} & \multirow{3}{*}{ t-test } \\
\hline & \multicolumn{3}{|c|}{ Kelompok Kontrol } & \multicolumn{3}{|c|}{ Kelompok Perlakuan } & & \\
\hline & Pre & Post & Change & Pre & Post & Change & & \\
\hline 1 & 2.43 & 2.47 & 0.04 & 2.36 & 2.84 & 0.48 & 0.44 & $2.93^{*}$ \\
\hline 2 & 2.83 & 3.04 & 0.21 & 2.75 & 3.07 & 0.32 & 0.11 & 0.78 \\
\hline 3 & 2.68 & 2.72 & 0.04 & 2.57 & 2.95 & 0.38 & 0.34 & $2.12^{*}$ \\
\hline 4 & 2.79 & 2.72 & -0.07 & 2.50 & 2.73 & 0.23 & 0.30 & $2.00^{*}$ \\
\hline 5 & 2.70 & 2.81 & 0.11 & 2.64 & 3.02 & 0.38 & 0.27 & $1.69^{*}$ \\
\hline 6 & 2.68 & 2.70 & 0.02 & 2.55 & 2.75 & 0.20 & 0.18 & 1.05 \\
\hline 7 & 2.57 & 2.68 & 0.11 & 2.57 & 2.77 & 0.20 & 0.09 & 0.56 \\
\hline 8 & 2.55 & 2.87 & 0.32 & 2.91 & 3.11 & 0.20 & -0.12 & -0.80 \\
\hline 9 & 2.13 & 2.11 & -0.02 & 2.07 & 2.11 & 0.04 & 0.06 & 0.40 \\
\hline 10 & 2.06 & 2.09 & 0.03 & 2.07 & 2.48 & 0.41 & 0.38 & $2.23^{*}$ \\
\hline 11 & 2.09 & 2.13 & 0.04 & 2.34 & 2.64 & 0.30 & 0.26 & 1.62 \\
\hline 12 & 2.79 & 3.15 & 0.36 & 3.05 & 3.39 & 0.34 & -0.02 & -0.11 \\
\hline 13 & 2.30 & 2.53 & 0.23 & 2.32 & 2.73 & 0.41 & 0.18 & 1.12 \\
\hline 14 & 2.49 & 2.45 & -0.04 & 2.68 & 2.64 & -0.04 & 0.00 & 0.00 \\
\hline 15 & 2.30 & 2.13 & -0.17 & 2.30 & 2.45 & 0.15 & 0.32 & $2.00^{*}$ \\
\hline 16 & 2.57 & 2.51 & 0.06 & 2.64 & 2.64 & 0.00 & 0.06 & 0.37 \\
\hline 17 & 2.51 & 2.34 & -0.17 & 2.55 & 2.68 & 0.13 & 0.30 & $1.76^{*}$ \\
\hline 18 & 2.49 & 2.49 & 0.00 & 2.48 & 2.77 & 0.29 & 0.29 & $1.81^{*}$ \\
\hline 19 & 2.23 & 2.38 & 0.15 & 2.32 & 2.66 & 0.34 & 0.19 & 1.26 \\
\hline 20 & 2.49 & 2.57 & 0.08 & 2.55 & 2.86 & 0.31 & 0.23 & 1.43 \\
\hline 21 & 2.55 & 2.51 & -0.04 & 2.45 & 2.70 & 0.25 & 0.29 & $1.81^{*}$ \\
\hline
\end{tabular}

* $\quad$ Signifikan pada $\mathrm{P}<0.05$ menggunakan t-test untuk perbedaan mean pada aitem pertanyaan. Lihat deskripsi item pada lampiran.

\section{PEMBAHASAN}

Pengaruh Model Microskill pada Kualitas Supervisi Klinik

Hasil penelitian dalam konteks pendidikan perawat ini menunjukkan perbedaan kualitas supervisi klinik antara model microskill dan konvensional. Hasil penelitian ini sesuai penelitian Furney ${ }^{5}$ bahwa pembimbingan klinik menggunakan model microskill meningkatkan kualitas supervisi pada residen. Residen yang memperoleh bimbingan klinik menggunakan model microskill menunjukkan kepuasan dan terjadi peningkatan motivasi untuk membaca lebih jauh. Bowen ${ }^{6}$ melaporkan bahwa peserta workshop one-minute preceptor menunjukkan peningkatan partisipasi bermain peran dan merasa puas dengan workshop yang diberikan.

Hasil yang sejalan tersebut menunjukkan bahwa intervensi yang diberikan sama efektifnya meskipun dalam konteks pendidikan profesi yang berbeda.
Meskipun tugas dalam proses pemberian feedback antara peran cure dan care memang berbeda, tetapi alur interaksi yang dipakai antara seorang pembimbing dan mahasiswa tidak banyak berbeda. Misalnya jika mahasiswa kedokteran menegakkan diagnosis penyakit, sedangkan mahasiswa keperawatan menegakkan diagnosis keperawatan. Alur interaksi yang dipakai sama mulai dari memberikan komitmen berkonsultasi, bertanyajawab dengan pembimbing, pemberian feedback oleh pembimbing dan juga merumuskan hal yang telah dipelajari ataupun yang perlu dipelajari lebih lanjut.

\section{Perubahan Kualitas Supervisi Klinik berdasarkan Aitem} Pertanyaan

Dari 21 aitem persepsi mahasiswa terhadap kemampuan dosen pembimbing klinik, terdapat 9 aitem yang signifikan berubah dengan memakai model microskill. Aitem tersebut terkait dengan lima tahap microskills yang 
terstruktur. Pada model ini "dosen pembimbing praktik klinik memberikan kesempatan untuk mempresentasikan kasus pasien" karena memang langkah satu harus memberikan kesempatan mahasiswa berinisiatif. Pendidikan klinik memerlukan peran aktif dan mandiri dari mahasiswa sehingga kesadaran pembimbing untuk memberi kesempatan kepada mahasiswa menjadi langkah awal keberhasilan bimbingan. Langkah kedua, dalam menjalin interaksi dengan mahasiswa tampak pembimbing sudah menunjukkan struktur yang jelas yaitu dengan "menanyakan rencana keperawatan pasien", "menanyakan rencana keperawatan yang telah dilakukan", "meminta untuk memberikan data yang mendukung diagnosis keperawatan yang disampaikan". Seringkali yang terjadi langkah kedua ini gagal dilakukan karena pembimbing langsung memberikan kritik dan menyalahkan mahasiswa sehingga proses bimbingan tidak berlanjut. Mahasiswa perlu digali lebih lanjut untuk menunjukkan pemahaman mereka secara komprehensif dan juga pembimbing dapat mengetahui aspek yang perlu diajarkan lebih lanjut. Langkah ketiga dan keempat berlangsung lebih baik karena pembimbing mulai "memberikan pujian apabila tindakan yang dilakukan benar" dimana hal ini jarang dilakukan pada model konvensional. Model bimbingan ini juga memperkuat pembimbing dalam "memberikan cara bagaimana menghindari kesalahan”, "mengajarkan konsep seputar kasus yang dipresentasikan", "mendorong mengaplikasikan konsep dalam melakukan praktik klinik". Secara keseluruhan mahasiswa merasakan bahwa bimbingan yang terstruktur dengan model microskills membuat pembimbing "membimbing dengan rasa percaya diri”".

Aitem yang tidak signifikan ada 12 buah yang mencakup langkah dua hingga lima. Kesulitan atau tidak adanya perubahan tersebut menunjukkan bahwa aitem yang dimaksud sulit untuk diubah hanya melalui pelatihan ini. Aitem di langkah kedua yang sulit diubah adalah kemampuan dosen pembimbing klinik "menanyakan diagnosis keperawatan pasien", "menanyakan data lain yang mendukung diagnosis keperawatan pasien", "menanyakan mengapa diagnosis keperawatan itu bisa terjadi”. Dari data tersebut tampak bahwa dosen kurang memberikan pertanyaan yang mengembangkan kemampuan mahasiswa dalam berfikir klinik secara rasional. Pelatihan melakukan interaksi yang membangun kemampuan berfikir klinik mungkin diperlukan.

Langkah ketiga yaitu memberikan umpan balik yang positif merupakan kemampuan yang paling kurang berubah. Di dalam langkah ini pembimbing kurang mampu mengubah caranya "memberikan komentar spesifik dalam menangani kasus pasien", "memberikan komentar bahwa tindakannya sangat membantu pasien", "membangkitkan rasa percaya diri", "memberikan komentar yang berdampak positif", "memberikan kesempatan untuk melakukan evaluasi diri atas asuhan keperawatan yang dilakukan kepada pasien". Tata cara pemberian umpan balik yang nyaman dan dapat diterima dengan baik seharusnya dikuasai oleh pembimbing. Langkah ke empat dan kelima juga perlu ditingkatkan yaitu sesegera mungkin "memberikan koreksi bila melakukan kekeliruan”, "menasehati agar kesalahan yang dilakukan tidak terulang di masa yang akan datang", "memberikan kesempatan untuk mendiskusikan kasus yang dihadapi", dan "memberikan instruksi yang mudah diingat".

Dari 12 aitem yang tidak signifikan di atas, secara tidak langsung ditunjukkan bahwa dalam praktik keperawatan pembimbingan masih belum mendapatkan perhatian khusus. Memerlukan pelatihan untuk melakukan aitemaitem supervisi di atas, sehingga menguasai kemampuan dan keterampilan adekuat dalam memberikan bimbingan. Pembelajaran klinik yang selama ini dilakukan oleh dosen pembimbing klinik sesuai dengan pengalaman, kemampuan, dan gaya dari masing-masing dosen pembimbing. Belum adanya keseragaman dalam sistem bimbingan yang diberikan kepada mahasiswa sehingga mahasiswa seringkali menyesuaikan dengan cara bimbingan yang diberikan oleh dosen pembimbing. Kemampuan supervisor klinik menjadi salah satu faktor yang penting dalam proses pembelajaran klinik.

Squires $^{4}$ menegaskan bahwa pendidikan klinik membutuhkan supervisor klinik yang mempunyai kemampuan membimbing mahasiswa. Untuk mencapai kemampuan itu, mereka harus dipersiapkan agar mencapai kondisi yang diinginkan. Hal ini diperkuat oleh Harden ${ }^{7}$ bahwa salah satu faktor penentu keberhasilan pendidikan klinik adalah faktor supervisi klinik. Supervisi klinik yang berkualitas memerlukan pembimbing klinik yang kompeten dan profesional.

Hasil penelitian Furney ${ }^{5}$ dinyatakan dalam analisis mean diffrerence, dari 14 aitem kemampuan pembimbing hanya 5 aitem yang signifikan dan 9 aitem tidak signifikan. Adapun aitem yang mengalami peningkatan adalah "melibatkan dalam proses pengambilan keputusan", 
"mengevaluasi pengetahuan, memberikan dorongan untuk berbuat lebih baik", "memberikan umpan balik secara teratur", "memotivasi untuk selalu belajar". Ada kesamaan hasil aitem yang mengalami peningkatan yaitu "kesempatan untuk mempresentasikan kasus pasien", "menanyakan rencana keperawatan pasien", "menanyakan rencana keperawatan yang telah dilakukan", "meminta untuk memberikan data yang mendukung diagnosis keperawatan yang disampaikan", dan "melibatkan dalam proses pengambilan keputusan”. Hal ini karena pembimbing merasa bertanggungjawab dalam hal untuk menggali kebutuhan belajar mahasiswa untuk membantu proses analisis mahasiswa terhadap kasus yang dihadapi.

Hal lain yang sama adalah "mendorong mengaplikasikan konsep dalam melakukan praktik klinik", "memberikan pujian apabila tindakan yang dilakukan benar", "memberikan cara bagaimana menghindari kesalahan", "membimbing dengan rasa percaya diri", dan "memberikan dorongan untuk berbuat lebih baik", "memotivasi untuk selalu belajar”. Kesamaan ini karena seorang pembimbing klinik adalah sosok orang yang lebih senior yang senang jika melihat anak didiknya sukses sehingga pemberian motivasi merupakan hal yang penting untuk selalu diberikan kepada mahasiswa.

Persamaan dalam mengajarkan konsep seputar kasus yang dipresentasikan, dan mengevaluasi pengetahuan mahasiswa ini menunjukkan bahwa praktik klinik perlu selalu didukung dengan konsep yang sesuai, sehingga mahasiswa dengan bekal pengetahuan yang tepat akan mudah dalam melakukan praktik klinik. Tanpa pemahaman konsep akan terjebak pada ritual monoton dan hilangnya pemaknaan dari suatu pengalaman klinik yang diperoleh.

Hasil penelitian ini juga menunjukkan perbedaan keteraturan dosen pembimbing dalam memberikan feedback. Pemberian feedback memerlukan pelatihan khusus, cara memberikan feedback yang positif dan feedback yang spesifik. Keterbatasan dosen pembimbing dalam keterampilan memberikan feedback mempengaruhi persepsi mahasiswa terhadap bimbingan yang dilakukan. Sejalan dengan fakta tersebut Frisch ${ }^{3}$ mengemukakan bahwa pembimbing klinik harus mendapat pelatihan agar menjadi pembimbing yang efektif termasuk cara mengevaluasi mahasiswa. Salah satu faktor penentu keberhasilan pendidikan klinik adalah pembimbing harus mengetahui tujuan pendidikan klinik dan menjelaskannya kepada mahasiswa. Khusus dalam hal pemberian feedback hendaknya pembimbing menggunakan teknik yang konstruktif dan spesifik.

Aitem yang tidak mengalami peningkatan secara signifikan kebanyakan adalah hal-hal yang berhubungan dengan keterampilan khusus pemberian feedback yang harus dimiliki oleh seorang pembimbing klinik. Keterampilan feedback membutuhkan pelatihan dan pembinaan khusus agar bisa diimplementasikan dengan baik dari pembimbing klinik. Sekedar pelatihan singkat pastilah belum memuaskan, oleh karena itu diperlukan penyegaran dan pembinaan yang berkelanjutan sehingga keterampilan ini menjadi semakin baik. Kurangnya perhatian pembimbing klinik untuk belajar dalam hal pemberian umpan balik akan mengurangi efektifitas kualitas supervisi klinik kepada mahasiswa.

McLeod $^{1}$ menjelaskan bahwa diperlukan perencanaan untuk mengidentifikasi proses yang mendukung tercapainya tujuan untuk memperoleh keterampilan dan mengajarkan mahasiswa di klinik. Pendidikan klinik perlu direncanakan secara sistematik, artinya dipikirkan mulai target kompetensi. Pendidikan klinik juga harus terstruktur, artinya tidak tergantung hanya pada apa yang ada di lapangan tetapi harus ditetapkan apa yang akan dicapai. Perencanaan ini bukan hanya di tingkat institusi pendidikan saja, tetapi juga menyangkut tempat pendidikan baik di rumah sakit atau tempat perawatan lainnya.

\section{KESIMPULAN}

Berdasarkan hasil penelitian dan pembahasan di atas, maka dapat disimpulkan sebagai berikut:

1. Model microskills lebih efektif untuk meningkatkan kualitas supervisi klinik mahasiswa keperawatan dibandingkan model konvensional.

2. Kualitas supervisi klinik yang mengalami peningkatan adalah pada aspek kinerja supervisor yang bersifat umum sedangkan kinerja supervisor yang membutuhkan keahlian khusus seperti pemberian feedback tidak mengalami peningkatan yang berarti.

3. Pembelajaran klinik model microskills merupakan model bimbingan klinik yang mudah untuk dipelajari dan mudah diterapkan dalam membimbing praktik klinik mahasiswa. 


\section{SARAN}

Beberapa saran yang dapat dirumuskan dari hasil penelitian ini adalah:

1. Mahasiswa pada masa orientasi perlu dilatih dalam model bimbingan klinik micro skills, sehingga ia akan memahami langkah-langkah bimbingan yang dilakukan, dapat melakukan persiapan dengan baik dan dapat memperoleh manfaat yang besar dari bimbingan tersebut.

2. Salah satu penentu keberhasilan pembelajaran klinik adalah kemampuan pembimbing klinik. Oleh karena itu pembimbing harus senantiasa mengembangkan diri, memantau, dan menjaga mutu bimbingan klinik serta mengikuti inovasi di bidang pendidikan kesehatan khususnya model bimbingan klinik. Hal ini bisa dilakukan dengan belajar melalui pelatihan-pelatihan ataupun memakai sumber daya yang sekarang tersedia luas.

3. Menerapkan inovasi di bidang pendidikan kesehatan khususnya pembelajaran klinik model microskill dalam memberikan bimbingan praktik kepada mahasiswa. Salah satunya dengan meningkatkan sumber daya manusia dengan mengikuti pelatihan inovasi pendidikan kesehatan dan belajar lebih lanjut dalam bidang pendidikan kesehatan dan kedokteran.
4. Bagi peneliti yang berminat pada permasalahan pembelajaran klinik, dapat mengembangkan variabel lain yang mempengaruhi kualitas supervisi klinik dan waktu penelitian yang lebih lama.

\section{DAFTAR PUSTAKA}

1. McAlister L, Lincoln M, McLeod S, Maloney D, editors. Facilitating learning in clinical settings. London: Stanley Thornes, USA: Singular Press; 1997.

2. Spencer J. $\mathrm{ABC}$ of learning and teaching in medicine: learning and teaching in the clinical environment. BMJ. 2003; 326:591-4.

3. Frisch SR, Boucher FG, Charbonneau S, Lapointe C, Turcotte R. Increasing the effectiveness of clinical supervision. Can Med Assoc J. 1984;131(6):569-72.

4. Squires BP. Improving clinical teaching: a sporadic or sustained effort? Can Med Assoc J. 1986;134:8778.

5. Furney SL, Orsini AN, Orsetti KE, Stern DT, Gruppen LD, Irby DM. Teaching the one-minute preceptor. J Gen Intern Med. 2001; 16(9):620-4.

6. Bowen JL, Eckstrom E, Muller M, Janey E. Enhancing the effectiveness of one-minute preceptor faculty development workshops. Teaching and Learning in Med. 2006;18(1):35-41.

7. Harden RM, Crosby JR, Davis MH. AMEE guide no. 14 outcome-based education: part 1 an introduction to outcome-based education. Med Teach. 1999; 21(1):7-14 


\section{LAMPIRAN}

NO PERNYATAAN

1 Dosen pembimbing praktik klinik memberikan kesempatan kepada saya untuk mempresentasikan kasus pasien.

2 Dosen pembimbing praktik klinik menanyakan kepada saya diagnosis keperawatan pasien.

3 Dosen pembimbing praktik klinik menanyakan rencana keperawatan pasien.

4 Dosen pembimbing praktik klinik menanyakan rencana keperawatan yang telah dilakukan.

5 Dosen pembimbing praktik klinik meminta saya untuk memberikan data yang mendukung diagnosis keperawatan yang saya disampaikan.

6 Dosen pembimbing praktik klinik menanyakan data lain yang mendukung diagnosis keperawatan pasien.

7 Dosen pembimbing praktik klinik menanyakan mengapa diagnosis keperawatan itu bisa terjadi.

8 Dosen pembimbing praktik klinik memberikan komentar yang tidak spesifik kepada saya dalam menangani kasus pasien.

9 Dosen pembimbing praktik klinik memberikan komentar bahwa tindakan saya sangat membantu pasien.

10 Dosen pembimbing praktik klinik memberikan pujian apabila tindakan yang saya lakukan benar.

11 Dosen pembimbing praktik klinik membangkitkan rasa percaya diri saya.

12 Dosen pembimbing praktik klinik memberikan komentar yang berdampak negatif kepada saya.

13 Dosen pembimbing praktik klinik memberikan kesempatan kepada saya untuk melakukan evaluasi diri atas asuhan keperawatan yang saya lakukan kepada pasien.

14 Dosen pembimbing praktik klinik sesegera mungkin memberikan koreksi bila saya melakukan kekeliruan.

15 Dosen pembimbing praktik klinik memberikan cara bagaimana menghindari kesalahan.

16 Dosen pembimbing praktik klinik menasehati saya agar kesalahan yang dilakukan tidak terulang di masa yang akan datang.

17 Dosen pembimbing praktik klinik mengajarkan konsep seputar kasus yang saya presentasikan.

18 Dosen pembimbing praktik klinik mendorong saya mengaplikasikan konsep dalam melakukan praktik klinik.

19 Dosen pembimbing praktik klinik memberikan instruksi yang mudah diingat.

20 Dosen pembimbing praktik klinik memberikan kesempatan kepada saya untuk mendiskusikan kasus yang dihadapi.

21 Dosen pembimbing praktik klinik membimbing saya dengan rasa percaya diri. 